Explicit vs. Implicit Country Stereotypes as Predictors of Product Preferences: Insights from the Stereotype Content Model

Adamantios Diamantopoulos

Professor

University of Vienna, Faculty of Business, Economics and Statistics

Department of International Marketing

Arnd Florack

Professor

University of Vienna, Faculty of Psychology

Department of Applied Psychology

Georgios Halkias (corresponding author)

Assistant Professor

University of Vienna, Faculty of Business, Economics and Statistics

Department of International Marketing

Johanna Palcu

Ph.D. candidate

University of Vienna, Faculty of Psychology

Department of Applied Psychology

"This is a post-peer-review, pre-copyedit version of an article published in Journal of International Business Studies. The definitive publisher-authenticated version Diamantopoulos, A., Florack, A., Halkias, G., \& Palcu, J. (2017). Implicit country stereotypes as predictors of product preferences: Insights from the stereotype content model. Journal of International Business Studies, 48, 1023-1026.

doi: 10.1057/s41267-017-0085-9 is available online at https://link.springer.com/article/10.1057/s41267-0170085-9"

Running title: Explicit vs. Implicit Country Stereotypes

Acknowledgement: The authors acknowledge the Austrian Science Fund (FWF) for supporting this study (Research Grant: P26740). In addition, the authors would like to thank Professor Dan Bello (JIBS editor) and three anonymous reviewers for their constructive comments and suggestions on previous versions of this manuscript. 


\title{
Explicit vs. Implicit Country Stereotypes as Predictors of Product Preferences: Insights from the Stereotype Content Model
}

\begin{abstract}
Drawing on the Stereotype Content Model (SCM), we investigate the impact of both explicit and implicit country stereotypes on consumer preferences. In Study 1, we show that the competence dimension of the SCM (measured both explicitly and implicitly) drives purchase intention by positively influencing brand affect. In Study 2, we disentangle further the role of explicit and implicit stereotypes and show that explicit judgments of country competence are better predictors of deliberate consumer choices, whereas implicit judgments of country warmth dominate spontaneous choice. Managerially our findings indicate that sole reliance on explicit stereotypes may result in an incomplete picture of consumers’ responses to country-of-origin cues.
\end{abstract}

Keywords Country of origin, Stereotype Content Model, implicit stereotypes, spontaneous and deliberate choice, IAT 


\section{INTRODUCTION}

Largely as a consequence of marketplace globalization, consumers are increasingly exposed to brands with different countries of origin (COO), the latter referring to the "country which a consumer associates with a product or brand as being its source, regardless of where the product is actually produced” (Jaffe \& Nebenzahl, 2006: 29). In this context, a large body of research has sought to examine how COO cues can render symbolic value to a brand, act as a signal of quality, affect perceptions of risk, and influence consumers' product choices (for relevant reviews, see Magnusson \& Westjohn, 2011; Maheswaran \& Chen, 2009).

Recently, however, $\mathrm{COO}$ research has drawn substantial criticism as a result of two interrelated shortcomings (Samiee, 2010, 2011; Usunier, 2006). The first shortcoming "relates to the operationalization of the $\mathrm{COO}$ construct per se, which has been described as relatively ambiguous, because it is used in a variety of ways by researchers” (Samiee \& Leonidou, 2011: 72). Although there is certainly no shortage of measures capturing COO perceptions (e.g., no fewer than 30 country image scales were reviewed by Roth \& Diamantopoulos, 2009), most of the relevant operationalizations lack solid theoretical underpinnings. Accordingly, researchers have been urged to “identify theories established in more mature disciplines [...] and to transfer them to explain COO effects” (Samiee \& Leonidou, 2011: 82).

A second shortcoming of extant $\mathrm{COO}$ research is its almost exclusive reliance on the explicit (direct) measurement of country stereotypes - based on consumers’ self-reports from standardized questionnaires - whilst neglecting the implicit (indirect) nature of such perceptions (for an exception, see Martin, Lee, \& Lacey, 2011). However, self-reports are susceptible to impression management and social desirability bias (Podsakoff, MacKenzie, \& Podsakoff, 2012) and are based on the assumption that respondents are able to introspectively access relevant information in memory and verbally articulate it; this assumption is not always warranted (Fazio \& Olson, 2003; Greenwald \& Banaji, 1995; Herz \& Diamantopoulos, 2013a). Moreover, “activated associations assessed by implicit measures can influence overt behavior, even when these associations are rejected as invalid in standard self-report measures” (Gawronski, 2009: 146). In sum, assessing country stereotypes only 
with explicit measures is likely to result in a partial, and possibly distorted, picture of consumer perceptions.

In this paper, we employ the Stereotype Content Model (SCM; Fiske et al., 2002) to investigate how explicit as well as implicit country stereotypes influence consumer preferences for brands with different origins. The SCM offers a parsimonious, theory-based approach for effectively operationalizing country stereotypes (Cuddy et al., 2009; Glick et al., 2006) that are not tied to any product class or category idiosyncrasies, thus enhancing generalizability (Josiassen et al., 2013). Moreover, its dimensions have been shown to be amenable to implicit measurement techniques (Carlsson \& Björklund, 2010), thereby enabling direct comparison of the relative influence of explicit and implicit country stereotypes on consumer responses.

We conduct two complementary studies. In Study 1, we examine how explicit and implicit country stereotypes drive purchase intention by generating more positive affective responses toward a brand. In doing so, we also offer insights into the extent to which explicit and implicit stereotypes converge or diverge. In Study 2, we investigate whether explicit (implicit) stereotypes are better predictors of deliberate (spontaneous) consumer choices and also explore the role of the SCM dimensions under these different purchase situations.

Our intended contribution is threefold. First, we enrich extant COO theory by revealing whether the content of a country stereotype that is based on direct/explicit measurement is similar to that produced by indirect/implicit measurement. Second, we test the predictive validity of the SCM in a COO context using both explicit and implicit measures of its dimensions and linking them to key, brand-level behavioral outcomes. Clearly, if explicit and implicit country stereotypes are found to diverge or to have different impacts on important outcome variables, solely relying on either one of them would lead to suboptimal managerial decisions. Third, we contribute to a deeper understanding of COO effects by demonstrating that explicit versus implicit country stereotypes, as well as their constituent dimensions, can have a differential impact on consumer choice depending on the decisionmaking context (i.e., deliberate vs. spontaneous choices). 


\section{COUNTRY STEREOTYPES AND THE STEREOTYPE CONTENT MODEL}

A stereotype is an oversimplified and generalized set of beliefs about the characteristics of a social group that tends to be uniform within a given population (Greenwald \& Banaji, 1995). The central tenet of stereotyping is the attribution of the characteristics of the whole group to specific individuals, merely because of their membership in the group (Levy, Stroessner, \& Dweck, 1998). For example, given the stereotype that Germans are disciplined and efficient, every time one encounters a German person, s/he will tend to assume that this individual possesses these characteristics. The content of stereotypes reflects a cognitive dimension of social perception and research shows that established stereotypes often serve as the primary basis for forming judgments about social groups and their members (Levy et al., 1998).

A common form of stereotypical perceptions refers to how people see different countries or nationalities (Samiee, 1994). Through the process of socialization as well as the exposure to information about various countries, individuals develop country-level categories or stereotypes which reflect their perceptions about the typical features each country possesses (Maheswaran, 1994). Such perceptions apply not only to people but also to every attitude object for which category membership is established. As such, whenever a product or brand is identified as coming from a certain country, stereotypical country-level beliefs intuitively transfer to the impressions individuals form about it, generate inferences, and stimulate affective responses toward the product (Herz \& Diamantopoulos, 2013b; Liu \& Johnson, 2005). In other words, the stereotypes people have for different countries influence their brand perceptions and subsequent preferences.

One of the most prominent theoretical frameworks for understanding the nature of stereotypes is the Stereotype Content Model (SCM; Fiske et al., 2002), according to which every social group can be described along two fundamental dimensions, namely warmth and competence. In a COO context, the warmth dimension reflects beliefs about how friendly or good-natured a particular country is perceived to be, whereas the competence dimension captures beliefs with regard to the country's capabilities and efficiency (Cuddy, Fiske, \& Glick, 2008). These two stereotype content dimensions are positively valenced and lead to more favorable action tendencies toward the members of a given 
stereotypical category (Cuddy, Fiske, \& Glick, 2007). Hence, the more a country is characterized by high warmth and/or high competence, the more positive consumers' responses toward products coming from that country are expected to be (Chen, Mathur, \& Maheswaran, 2014; Maher \& Carter, 2011).

While the SCM's ability to specifically capture country stereotypes has been repeatedly validated (Cuddy et al., 2009; Glick et al., 2006; Kervyn et al., 2008), extant applications of the SCM in COO research (e.g., Chen et al., 2014; Halkias, Davvetas, \& Diamantopoulos, 2016; Maher \& Carter, 2011) have relied exclusively on explicit (self-report) measures of country stereotypes. However, as further elaborated below, implicit stereotypical associations are particularly germane to COO effects and ignoring them can be problematic.

\section{EXPLICIT VS. IMPLICIT COUNTRY STEREOTYPES}

$\mathrm{COO}$ research has been invariably based on the assumption that consumers view $\mathrm{COO}$ cues as diagnostic information, which they "deliberately use in their evaluation of products” (Liu \& Johnson, 2005: 87, emphasis added). However, the extent to which one’s own thoughts and behavior are under one’s own intentional control is a long-standing question, with social cognition literature documenting that many social phenomena are unintentional or automatic in nature (Bargh, Chen, \& Burrows, 1996). In fact, mere exposure to a stereotypical cue may activate stereotypical associations without conscious control or attention by the individual (Fazio \& Olson, 2003; Greenwald \& Banaji, 1995); thus the presence of a COO cue may automatically stimulate country-related stereotypes that subsequently impact purchase behavior (Herz \& Diamantopoulos, 2013b).

Overall, relevant research not only suggests that consumers may be reluctant to admit their stereotypical beliefs but also that they may be unaware of their own stereotypes (Liu \& Johnson, 2005; Martin et al., 2011). This lack of awareness inevitably implies that consumers will often not be able to reveal their true country stereotypes through self-report measures based on direct questioning (Herz \& Diamantopoulos, 2013a). To capture these “latent” country stereotypical associations, implicit measurement approaches need to be adopted in light of their "potentially superior ability to gather accurate construct measurement data despite consumers' reluctance or inability to provide them” 
(Dimofte, 2010: 933). Implicit measures are implicit in the sense that they assess individuals' beliefs and attitudes indirectly, through tasks that do not reveal the content of interest (Fazio \& Olson, 2003;

Gawronski \& Bodenhausen, 2007; Petty, Fazio, \& Brinol, 2009). This stands in contrast to explicit (i.e., self-report) measurements in which people are usually fully aware that their beliefs and attitudes are being the subject of study. Implicit measures have been developed as counterparts to self-report measures and have been found to demonstrate unique predictive validity (Cunningham, Preacher, \& Banaji, 2001; Nosek \& Smyth, 2007). In our studies we apply one of the most prominent implicit measures of attitudes and stereotypes: the Implicit Association Test (IAT; Greenwald, McGhee, \& Schwartz, 1998). The IAT does not ask participants to report stereotypes explicitly; instead it "assesses strengths of associations between concepts by observing response latencies in computer-administered categorization tasks” (Greenwald et al., 2009, p. 18). Thus, implicit country stereotypes can be readily derived from participants' reactions to the IAT4 .

\section{STUDY 1}

\section{Research Model and Hypotheses}

Study 1 seeks to assess the predictive validity of the SCM using both implicit and explicit measures of its dimensions as well as to investigate whether the resulting country stereotypes converge or diverge in terms of predicting consumer preferences (Figure 1).

\section{INSERT FIGURE 1 ABOUT HERE}

Consistent with prior research (Chen et al., 2014; Halkias et al., 2016; Maher \& Carter, 2011) and given the large conceptual distance between (a) one's established beliefs about a country (i.e., the country stereotype), and (b) one's decision to purchase a particular brand from that country, no direct effects of either warmth or competence on purchase intentions are anticipated. According to the SCM, people hold explicit and implicit judgments about a country's warmth and competence and "these judgments can form the basis for positive or negative affect elicited by the stereotypes” (Chen et al., 
2014: 1035). In other words, stereotypical judgments about the brand origin elicit positive (negative) responses that carry over to the overall brand assessment which, in turn, encourages (discourages) purchase intentions (Chaudhuri \& Holbrook, 2001). Therefore, positively valenced (explicit or implicit) country stereotypes in terms of warmth and competence will generate more favorable affective reactions toward brands from that country that will subsequently lead to more positive behavioral intentions.

Hypothesis 1: Explicit judgments of (a) competence and (b) warmth have a positive influence on brand affect, which then positively impacts purchase intention.

Hypothesis 2: Implicit judgments of (a) competence and (b) warmth have a positive influence on brand affect, which then positively impacts purchase intention.

Literature suggests that explicit and implicit measures generally tap into different aspects of the concept being measured (Gawronski \& Bodenhausen, 2006; Greenwald et al., 1998). Implicit measures account for associations that are uncontrollable and are automatically evoked in memory, whereas explicit measures capture beliefs that result from reflective thought processes (Strack \& Deutsch, 2004). These two sets of measures do not necessarily coincide as oftentimes individuals are either not willing to report what they really think or they cannot access their true thoughts (Greenwald \& Banaji, 1995; Podsakoff et al., 2012). Thus, to the extent that both types of stereotypes impact consumer responses (as proposed by H1 and H2), their contribution is expected to be nonoverlapping, explaining different parts of the variance in the outcome variables.

Hypothesis 3: Explicit and implicit judgments of competence and warmth have distinct and non-overlapping influences on brand affect and, through it, on purchase intention.

\section{Method}

Participants and design. Two hundred eighty-nine Austrian consumers (53\% female, $M_{\text {age }}=37.38$, $\left.S D_{\text {age }}=10.47\right)$ were recruited in a between-subjects, web-based study conducted by a professional 
marketing research agency (see Web Appendix A1, Table A1.1). In terms of GDP and demographic composition, Austria resembles countries typically used in prior COO research (e.g., Denmark, the Netherlands) and is strongly engaged in international trade with a significant volume of imported goods (approximately 50\% of its GDP in 2014).

Participants were randomly presented with one of six well-known brands from different countries (i.e., Armani/Italy, Mercedes/Germany, Kellogg’s/USA, Sony/Japan, IKEA/Sweden, and Evian/France) and completed an online questionnaire assessing their brand perceptions as well as their (explicit and implicit) country stereotypes. To avoid priming effects, respondents completed the purchase intention scale first (i.e., at the beginning of the survey), while stereotypes measurement was undertaken towards the end of the survey; furthermore, the order of exposure to explicit and implicit measures of the SCM dimensions was counterbalanced.

Explicit country stereotypes. Consistent with relevant studies using the SCM (Cuddy et al., 2009; Fiske et al., 2002; Kervyn et al., 2008; Maher \& Carter, 2011), explicit country stereotypes were assessed by asking respondents to indicate their beliefs about how most people view the target countries along the dimensions of warmth (friendly, good-natured, kind, warm) and competence (capable, efficient, intelligent, competent).

Implicit country stereotypes. Implicit country stereotypes were assessed with a SingleCategory Implicit Association Test (SC-IAT; Karpinski \& Steinman, 2006; see also Bluemke \& Friese, 2008) that was seamlessly integrated into the online questionnaire as a live link (see Web Appendix A2) ${ }^{1}$. Each country was represented by seven country-specific target words (e.g., Sweden: Stockholm, ABBA, Fjord) that were pretested for suitability (see Web Appendix A3, Table A3.1). Consistent with relevant research (Judd et al., 2005; Kervyn et al., 2008), the negative and positive poles of the SCM dimensions were each represented by seven target words (e.g., warmth positive: warm, friendly; warmth negative: cold, unfriendly; competent positive: competent, capable; competence negative: incompetent, incapable). The order of appearance of the country-related target words and the SCM dimensions was randomized. Participants performed a separate SC-IAT for each stereotype dimension. Whether they first performed the SC-IAT for warmth or competence was also counterbalanced. 
Separate $d$-measures for the warmth and competence SC-IATs were computed based on Greenwald, Nosek and Banaji (2003); see Web Appendix A4. Error rates ranged from 0\% to 19.06\% $(M=3.69 \%, S D=3.22)$. Participants $(\mathrm{n}=16)$ with more than $10 \%$ of their reactions faster than $300 \mathrm{~ms}$ and/or more than $30 \%$ errors in any of the combined categorization blocks were excluded (Bluemke \& Friese, 2008).

Dependent and control variables. Participants provided ratings on seven-point scales for brand affect (Chaudhuri \& Holbrook, 2001) and purchase intention (Dodds, Monroe, \& Grewal, 1991). To avoid confounding effects due to previous experiences with the brand, brand familiarity was also included as a control variable. Finally, a marker variable was included to enable the assessment of common method variance (CMV) between the explicit stereotype measures and the outcome variables. The measurement scales and psychometric properties of all model variables are summarized in Table 1, while assessment of the CMV is detailed in the Web Appendix A6.

\section{INSERT TABLE 1 ABOUT HERE}

\section{Measure Validation}

We investigated the unidimensionality, reliability, and validity of our measures with a confirmatory factor analysis using LISREL $9.2^{2}$. Model fit was satisfactory $\left(\chi^{2}=389.775\right.$, DF $=133$; RMSEA = 0.082; CFI $=0.955 ;$ SRMR $=0.040$ ). Factor loadings, $t$ values, Cronbach’s alpha, composite reliability (CR), and average variance extracted (AVE) all indicated a high level of reliability and convergent validity (see Table 1). Discriminant validity was also established; for each latent variable, the corresponding AVE was much higher than its squared correlation with the other latent variables in the model (see Table 2).

\section{INSERT TABLE 2 ABOUT HERE}

Warmth and competence were positively correlated when measured either explicitly ( $r=.503$, $p<.001)$ or implicitly $(r=.179, p<.01)$. However, the results revealed no relationship between explicitly and implicitly assessed country stereotypes on either the warmth $(r=.012$, n.s.) or 
competence dimensions ( $r=.038$, n.s.). This indicates a clear dissociation of respondents' explicit and implicit stereotypical assessments of the same country.

\section{Structural Model}

The estimation of the structural model in Figure 1 resulted in a good fit $\left(\chi^{2}=393.984, \mathrm{DF}=137\right.$; RMSEA $=0.080 ;$ CFI $=0.955$; SRMR $=0.042)$. Explicit competence $(\beta=.180, p=.003)$ and implicit competence ( $\beta=.094, p=.040$ ) both had positive impacts on brand affect thus supporting H1a and H1b. Warmth - whether explicitly- or implicitly-measured - did not show a significant influence; hence H2a and H2b were not supported. As expected, brand affect positively and strongly influenced purchase intention $(\beta=.458, p<.001)$. In addition, the control variable brand familiarity had significant effects on both brand affect $(\beta=.431, p<.001)$ and purchase intention $(\beta=.472, p<$ .001). Twenty-seven percent of the variance in brand affect and $63.40 \%$ of the variance in purchase intention are explained by the model relations, thus indicating large effect sizes (Cohen, 1988).

To test the mediating relationships, we compared our hypothesized model in Figure 1 with an alternative model that also included direct links from the stereotype dimensions to purchase intention. No improvement in model fit was obtained $\left(\Delta \chi^{2}=4.071, \mathrm{DF}=4\right.$, n.s. $)$ and none of the direct links were significant, indicating full mediation. As Table 3 illustrates, the relevant significant indirect paths were competence $e_{\text {explicit }} \rightarrow$ brand affect $\rightarrow$ purchase intention $(\beta=.082, p=.004)$ and competence $_{\text {implicit }} \rightarrow$ brand affect $\rightarrow$ purchase intention $(\beta=.043, p=.042)$. These results were corroborated by a PROCESS analysis (Hayes, 2013) as discussed in the Web Appendix A6.

\section{INSERT TABLE 3 ABOUT HERE}

To test H3, we compared the fit of the model including both the explicit and implicit measures of warmth and competence as predictors with the fit of alternative models in which the paths from the explicit or implicit measures were, in turn, fixed to zero. Comparisons between our hypothesized model with the two alternative models revealed a significant deterioration in fit (exclusion of explicit 
measures: $\Delta \chi^{2}=9.84, \mathrm{DF}=2, p=.007$; exclusion of implicit measures: $\Delta \chi^{2}=5.74$, DF $=2, p=.056$ ). Thus, explicit and implicit country stereotypes have distinct and non-overlapping effects explaining unique parts of the variance in brand affect and, ultimately, purchase intention.

\section{Discussion}

Study 1 provides the first empirical attempt to assess the predictive validity of the SCM on consumer response variables using both explicit and implicit measures of country stereotypes. The results reveal full dissociation between the resulting stereotypes (on both SCM dimensions) and indicate that explicit and implicit judgments of competence (but not warmth) elicit a more positive affective assessment of the brand and, through it, a greater likelihood of purchasing that brand.

Study 2 further disentangles the findings of Study 1 by distinguishing between deliberate and spontaneous choice decisions and examining when explicitly- and implicitly-measured country stereotypes are more likely to dominate consumer preference. In doing so, Study 2 also explores in more detail the role of the two SCM dimensions in driving COO effects.

\section{STUDY 2}

\section{Conceptual Background and Hypotheses}

Social perception literature suggests that implicit and explicit measures are not only dissociated in the sense that they are not correlated (as Study 1 showed) but also in the kind of behavior they predict (Greenwald et al., 2009). More specifically, it has been demonstrated that explicit measures are more predictive of deliberate and controlled judgments, whereas implicit measures are better predictors of impulsive and less controlled behavior (Florack, Scarabis, \& Bless, 2001).

Drawing on the dissociative impact of implicit and explicit attitudinal measures in predicting consumer behavior (Scarabis et al., 2006; Friese, Hofmann, \& Wänke, 2008), we propose an analogous distinction in how implicit and explicit country stereotypes relate to product choices under deliberate versus spontaneous conditions. More specifically, and given that the research design 
employed in Study 1 assumed at least a fair amount of respondent deliberation in assessing their brand perceptions, for the deliberate choice condition we expect a pattern of results similar to that in Study 1; namely that only competence will drive product choice with explicit judgments having a stronger impact than their implicit counterparts.

Hypothesis 4: Under deliberate choice conditions, explicit country stereotypes in terms of competence are better predictors of product choice than their implicit counterparts.

Implicit measures capture associations that are rapidly and effortlessly activated and thus are pertinent to judgment formation based on impulsive processes (Strack \& Deutsch, 2004). Therefore, in spontaneous choice decisions, implicit country stereotypes should have a stronger impact on product choice than explicit stereotypes and we now anticipate that warmth will also influence consumer responses. Although there is consensus with regard to the diagnosticity of the competence dimension in shaping product preferences (Chen et al., 2014), judgments of warmth have generally been underrated in terms of their relevance in COO research (Maher \& Carter, 2011). However, extant research has failed to take the specific decision-making context into account and ignore the fact that warmth-based judgments are more readily retrieved and are particularly reliable when cognitive effort or availability is limited (Abele \& Bruckmueller, 2011; Willis \& Todorov, 2006). This implies that under spontaneous choice conditions, where decisions are typically made instantaneously and consumers do not spend a lot of time to deliberate on available information, the instrumentality of warmth-related information should be higher. Consequently, implicit judgments of warmth should become more diagnostic in spontaneous, as compared to deliberate, decisions and therefore both dimensions of the SCM should be effective in predicting choice likelihood.

Hypothesis 5: Under spontaneous choice conditions, implicit country stereotypes in terms of both competence and warmth are better predictors of product choice than their explicit counterparts. 


\section{Method}

Participants and design. Two hundred and eighty consumers (49\% female, $M_{\text {age }}=37.72, S D=10.34$ ) participated in a web-based choice experiment administered by the same research agency as in Study 1 (see Web Appendix A1, Table A1.2). The experiment involved a choice between two products associated with different countries (Germany and the USA) and consisted of three tasks. One task involved respondents being exposed to two sequentially presented versions of the IAT, one measuring implicit warmth (warmth-IAT) and the other measuring implicit competence (competence-IAT) with respect to the two target countries. The second task involved the completion of a set of direct measures capturing explicit warmth and competence country stereotypes. The third task involved a product choice that manipulated either a deliberate or a spontaneous choice decision. This resulted in a 2 (deliberate vs. spontaneous choice) $\times 2$ (explicit vs. implicit country stereotypes) mixed factorial design, with choice condition operationalized as a between-subjects factor and country stereotype assessment as a within-subjects factor. To control for carryover effects due to the experimental design employed, the order of the tasks as well as the order of presentation within the tasks was counterbalanced and no confounding effects were observed (see Web Appendix A9 for full details).

Explicit country stereotypes. Explicit judgments of warmth and competence were measured with the same self-report items as employed in Study 1. To obtain a relative measure between the two target countries, we computed the difference between the average scores of warmth (Cronbach's $\alpha=$ .819) and competence ( $\alpha=$.856) for Germany and the USA, respectively. Consequently, higher values indicate more favorable judgments of warmth and competence for Germany relative to the USA.

Implicit country stereotypes. We used a standard version of the Implicit Association Test (IAT; Greenwald et al., 1998) to measure participants’ implicit warmth and competence stereotypes with respect to Germany and the USA (see Web Appendix A7); this IAT assessed the associations between the two target categories (Germany and the USA) as well as the positive and negative poles of each attribute dimension (warm-cold/competent-incompetent) simultaneously in one task. Because participants made a choice between products from two different countries, a contrasting IAT was better suited to map the relative implicit stereotypes with respect to the two COOs than the SC-IAT used in Study 1. 
Similar to Study 1, country associations were represented by seven Germany-related (e.g., Oktoberfest, Munich) and seven US-related (e.g., baseball, New York) target words (see Web Appendix A3, Table A3.2). IAT scores were calculated using the scoring procedure proposed by Greenwald et al. (2003) (see Web Appendix A4). To form a relative measure, differences between the IAT scores were calculated and coded such that positive values indicate an association between Germany and warm/competent, whereas negative values indicate an association between the USA and warm/competent. The higher the absolute value, the stronger the association between the country and each stereotype dimension. IAT error rates ranged from $0 \%$ to $17.06 \%(M=4.56 \%, S D=3.41)$. Following the same exclusion criteria as those in Study 1, 27 participants (9\%) were dropped from the analysis.

Product choice. Participants were randomly assigned to one of two product choice conditions (see Web Appendix A8). Those in the spontaneous condition were instructed to spontaneously and rapidly indicate their choice likelihood between two product options (discussed below). In the deliberate choice condition, participants were told to thoroughly consider the different alternatives before indicating their choice likelihood and also provide a short written statement justifying their decision (Scarabis et al., 2006).

In both choice conditions, participants were presented with three pairs of electronic products (tablet PCs, external hard drives, and digital cameras). Within each pair, products were similar in appearance but varied in their features. The first two product pairs (tablet PCs and external hard drives) did not convey any COO information and simply served to familiarize participants with the experimental task. For the third product pair, participants were presented with two digital cameras that were labeled with different countries of origin (Germany vs. USA) and varied in three product features (pixel number, zoom width, and monitor size). The features of the cameras unambiguously indicated that one camera was superior to the other (e.g., higher pixel number). However, whether the superior camera was paired with Germany or the USA was randomized as was the side (left or right) on which the German/superior or German/inferior and USA/superior or USA/inferior camera appeared. This procedure resulted in eight possible display scenarios for the final choice task; participants were asked to indicate their choice likelihood on a six-point scale anchored at most likely 
Product A/most likely Product B. Responses were coded such that higher values indicated stronger preference for the German product.

\section{Experimental Controls and Preliminary Analysis}

The check for the effectiveness of the decision context manipulation, we compared the time it took respondents to indicate their final product preference between the deliberate and the spontaneous choice condition. Results showed that the decision time under the deliberate condition ( $M=33.16$ seconds, $S D=57.66)$ was significantly more than that under the spontaneous condition $(M=13.97$ seconds, $S D=9.19)$, confirming that our manipulation worked as intended $(t(278)=3.767, p<.001)$.

In terms of explicit stereotypical country perceptions, paired-sample $t$ tests showed that Germany was perceived to be significantly more competent $\left(M_{\mathrm{GER}}=3.59, S D_{\mathrm{GER}}=0.81 \mathrm{vs} . M_{\mathrm{USA}}=\right.$ 3.13, $\left.S D_{\mathrm{USA}}=0.78, t(279)=6.924, p<.001\right)$ and significantly less warm $\left(M_{\mathrm{GER}}=3.02, S D_{\mathrm{GER}}=0.75\right.$ vs. $\left.M_{\mathrm{USA}}=3.21, S D_{\mathrm{USA}}=0.81, t(279)=3.356, p=.001\right)$ than the USA. Regarding implicit stereotypical country perceptions, we ran one-sample $t$-tests with the IAT scores for competence and warmth. Specifically, mean $d$-values for warmth and competence were tested against zero, which would indicate that Germany and the USA are identical in terms of stereotype content. For competence, the mean IAT score was positive and significantly different from zero $(M=0.11, S D=$ 0.33, $t(279)=5.317, p<.001)$, indicating that Germany was perceived to be more competent than the USA. Interestingly, the difference in implicit warmth evaluations was also positive and significantly different from zero $(M=0.17, S D=0.35, t(279)=8.169, p<.001)$, showing that, in contrast to explicit stereotypical beliefs, Germany was implicitly perceived to be warmer than the USA.

\section{Hypothesis Testing}

To test H4, a multiple regression analysis was conducted with the implicit and explicit competence and warmth dimensions as predictors and choice likelihood in the deliberate condition as the outcome variable (Table 4). Results showed a significant effect of explicit competence ( $\beta=.236, p=.007$ ) but no influence of implicit competence ( $\beta=.125$, n.s.) on choice likelihood. Moreover, and consistent 
with Study 1, neither implicit nor explicit warmth were significant predictors of choice likelihood ( $\beta \mathrm{s}$ $\leq .063$, n.s.).

In the spontaneous choice condition, multiple regression analysis revealed that implicit stereotypical perceptions of warmth toward Germany (relative to the USA) significantly predicted the likelihood of choosing a product with a German (relative to a USA) COO label ( $\beta=.246, p=.005$ ). Neither implicit or explicit competence nor explicit warmth had an impact on choice likelihood $(\beta \mathrm{s} \leq$ .145, n.s.). Thus, consistent with H5, implicit country stereotypes dominate in predicting spontaneous consumer choice but it is only the warmth dimension of the SCM that drives this effect.

\section{INSERT TABLE 4 ABOUT HERE}

Similar to Study 1, warmth and competence were positively correlated for both explicit ( $r=$ $.159, p=.008)$ and implicit stereotypes $(r=.294, p<.001)$. However, unlike Study 1 , explicit and implicit country stereotypes were also found to positively correlate (albeit weakly) (warmth: $r=.197$, $p=.001$; competence: $r=.134, p=.025)$. Variations in intercorrelations between IAT scores and selfreport measures are regularly reported in relevant literature (for a meta-analysis, see Greenwald et al., 2009). Yet, the fact that different country stereotypes are effective in predicting brand preference under different choice conditions further illustrates their dissociative impact on consumer responses.

\section{Discussion}

Study 2 extends the findings of Study 1 by showing that the relative importance of implicit and explicit country stereotypes as well as the relative importance of warmth and competence depends on the type of decision-making context. When consumers make their decision deliberately, product choice is mainly influenced by explicit judgments of the COO’s competence. In contrast, when consumers make their choice spontaneously, only the implicit warmth dimension of the country stereotype effectively predicts the final outcome. Overall, our results indicate that implicit country 
stereotypes play a more important role in spontaneous consumer decisions than explicit country stereotypes do, whereas the opposite holds true for deliberate decisions.

\section{GENERAL DISCUSSION}

\section{Theoretical Implications}

We advance international marketing literature by integrating COO research with stereotype theory and by offering the first empirical investigation demonstrating the utility of the SCM for explaining COO effects using both direct (self-report) and indirect (IAT) country stereotype measures. Our findings make an important contribution to COO research by identifying when product choice is primarily driven by explicit or implicit country stereotypes and they offer evidence with regard to the differential instrumentality of the warmth and competence dimension of the SCM in an international marketing context. Several noteworthy implications emerge from our findings.

First, and foremost, we establish that implicit country stereotypes are indeed predictive of consumer responses and offer complementary insights to those provided by their explicit counterparts. Importantly, we are able to demonstrate the relevance of implicit stereotypical judgments with both real and fictitious brands, different target countries, and different evaluation contexts (i.e., independent vs. comparative brand evaluation).

Second, although both our studies support the idea that stereotypical associations of competence for a brand's COO have a strong influence on consumer responses, they do not endorse the view that judgments of warmth are not relevant for influencing consumer behavior. While Chen et al. (2014) argue that warmth-related country associations are generally nondiagnostic as a basis for product evaluations, Study 2 demonstrates that their ability to predict consumer responses depends on the decision context. When decisions are made spontaneously (as opposed to deliberately), implicit judgments of a COO’s warmth are more predictive of brand preference than judgments of competence. This finding resonates well with Cuddy et al.'s (2007) notion of the primacy of warmth as well as with relevant evidence indicating that warmth-related information is generally identified and 
processed faster than competence-related information (Abele \& Bruckmueller, 2011; Ybarra, Chan, \& Park, 2001).

Third, we offer insights with regard to the convergence/divergence of explicit vs. implicit country stereotypes by showing that explicit and implicit stereotypes are dissociated in the sense that they tap into distinct areas of consumer responses (Greenwald et al., 2009). Consequently, COO research that solely relies on explicit stereotypes is likely to provide an incomplete picture of consumers' perceptions of brand origins.

From a methodological perspective, our analysis confirms the psychometric properties of the self-report measures for competence and warmth originally proposed by Fiske et al. (2002) and shows how implicit assessments of the SCM dimensions can be derived from applying either the singlecategory IAT (SC-IAT; Karpinski \& Steinman, 2006) or the “standard” IAT (Greenwald et al., 1998). Future researchers are strongly encouraged to use these and other similar (e.g., GNAT; Nosek \& Banaji, 2001) tools to complement conventional measures of country stereotypes.

\section{Managerial Implications}

A key managerial implication of our findings is that country stereotypes based on self-reports of consumers may differ considerably from those derived through implicit measurement. This is illustrated in Figure 2, which positions the six countries used as stimuli in Study 1 on the dimensions of the SCM (Panel A: explicit stereotypes; Panel B: implicit stereotypes) $)^{3}$. For example, although France and Sweden have very different explicit stereotypes (with Sweden scoring significantly higher on both SCM dimensions), their implicit stereotypes are practically identical. Similarly, although based on self-reports - Italy appears to be much less competent than Japan, hardly any difference is observed when implicit stereotypes are compared ${ }^{5}$. Therefore, for managers wishing to leverage their brands' COO through brand communication, sole reliance on explicit country stereotypes may not advisable unless it can be demonstrated that the picture painted by the latter is consistent with that derived from implicit stereotypes. Note, in this context, that commercial providers of country image perceptions - such as the Anholt-GfK Nation Brands Index ${ }^{S M}$ or the FutureBrand Country Brand Index - are, without exception, based on direct questioning of respondents in different countries and 
do not employ any indirect measurement methods. In light of potential discrepancies between explicit and implicit country stereotypes as shown in Figure 2, international marketing managers are advised to use such services with caution.

\section{INSERT FIGURE 2 ABOUT HERE}

Another important managerial implication relates to the role of the competence dimension of the SCM. Specifically, the superiority of competence that has been highlighted in previous literature (e.g., Chen et al., 2014) does not seem to be generalizable to all decision contexts. For purchase decisions requiring deliberate processing, emphasizing the $\mathrm{COO}$ in brand communications is likely to be more effective for countries that are perceived to be high in competence. In fact, for deliberate decisions, judgments of warmth neither complement nor compensate for judgments of competence. In contrast, for spontaneous purchase decisions, (a) implicit country stereotypes dominate over explicit stereotypical beliefs, and (b) warmth-related country associations are more important than competence-related associations. The implication for managers is that for products characterized by an impulsive purchase motivation, warmth associations of the originating country should be emphasized in communication campaigns.

\section{Limitations and Future Research}

Replications of our study using different country-brand combinations and capturing additional product categories are clearly necessary to establish the generalizability and robustness of our findings. Issues such as the dissociation between explicit and implicit country stereotypes, their relative explanatory power, and the nature of the relationship between the warmth and competence dimensions should take center stage in future studies.

Moreover, no account was taken in our investigation of how the consumer's decision-making style - such as optimizing vs. satisficing (Parker, Bruine de Bruin, \& Fischhoff, 2007) - may influence the role of explicit and implicit stereotypes as well as the role of the warmth and competence dimensions. Consumer characteristics such as consumer ethnocentrism, affinity, and 
cosmopolitanism may also influence COO perceptions or moderate their impact on outcome variables (e.g., Oberecker, Riefler, \& Diamantopoulos, 2008; Zeugner-Roth, Zabkar, \& Diamantopoulos, 2015). Unfortunately, due to respondent burden concerns, it was not feasible to obtain information on these characteristics in the current investigation. In light of these limitations, future research incorporating additional subject-level controls and moderating variables is needed to confirm, refine, and further extend the current findings.

Fourth, the IAT procedures employed in the current investigation represent only a subset of the available techniques and by no means can they account for the totality of implicit country cognitions. Thus, the role of implicit country stereotypes should be further analyzed and corroborated by additional implicit measurement techniques. For example, drawing on the premise that longer and more frequent eye fixations on a particular cue indicate greater perceived importance (Reisen, Hoffrage, \& Mast, 2008), eye-tracking techniques could be employed to examine whether and to what extent consumers exposed to brand messages incorporating COO information attend to warmthand/or competence-related cues and how this relates to subsequent preference formation.

Finally, as our investigation only focused on implicit measures rather than implicit cues, future studies should also employ research designs that involve the unaided mention of $\mathrm{COO}$ as a factor potentially influencing consumers' decision making, thus generating evidence of the veracity of COO under more ecologically valid conditions. 


\section{ENDNOTES}

${ }^{1}$ The IAT is the most widely used instrument for the assessment of implicit cognitions and there is substantial evidence regarding its psychometric properties and robustness (for a review, see Greenwald et al., 2009). Moreover, it has been repeatedly proven to be effective in predicting outcome variables such as consumer evaluations and purchase intentions (Dimofte, 2010; Greenwald et al., 2009).

${ }^{2}$ The $d$-scores for the warmth and competence dimensions based on the SC-IAT procedure were specified as single-item measures by fixing their loadings to one and their error variances to zero.

${ }^{3}$ The explicit and implicit measures of country stereotypes have been converted to $z$-scores to be comparable.

${ }^{4}$ It is important to note that, by applying the IAT, it is the measurement of COO stereotypes that is implicit (indirect) and not the presentation of the COO cue. It is not the goal of our studies to show how and when implicit COO cues affect consumer behavior nor to investigate different presentation formats of $\mathrm{COO}$ cues. The authors would like to thank an anonymous reviewer for alerting to this important distinction.

${ }^{5}$ These conclusions are based on ANOVA tests and post-hoc comparisons with the explicit and implicit assessment of warmth and competence as dependent variables and the six countries in Figure 2 as the independent factor. Detailed results are available upon request from the authors. 


\section{REFERENCES}

Abele, A. E., \& Bruckmueller, S. 2011. The bigger one of the "Big Two"? Preferential processing of communal information. Journal of Experimental Social Psychology, 47(5): 935-948.

Bargh, J. A., Chen, M., \& Burrows, L. 1996. Automaticity of social behavior: Direct effects of trait construct and stereotype activation on action. Journal of Personality and Social Psychology, 71(2): 230-244.

Bluemke, M., \& Friese, M. 2008. Reliability and validity of the single-target IAT (ST-IAT): Assessing automatic affect towards multiple attitude objects. European Journal of Social Psychology, 38(6): 977-997.

Carlsson, R., \& Björklund, F. 2010. Implicit stereotype content: Mixed stereotypes can be measured with the implicit association test. Social Psychology, 41(4): 213-222.

Chaudhuri, A., \& Holbrook, M. B. 2001. The chain of effects from brand trust and brand affect to brand performance: The role of brand loyalty. Journal of Marketing, 65(2): 81-93.

Chen, C. Y., Mathur, P., \& Maheswaran, D. 2014. The effects of country-related affect on product evaluations. Journal of Consumer Research, 41(4): 1033-1046.

Cohen, J. 1988. Statistical power analysis for the behavioral sciences, (2nd ed.). Hillsdale, NJ: Lawrence Erlbaum.

Cuddy, A. J. C., Fiske, S. T., \& Glick, P. 2007. The BIAS map: Behaviors from intergroup affect and stereotypes. Journal of Personality and Social Psychology, 92(4): 631-648.

Cuddy, A. J. C., Fiske, S. T., \& Glick, P. 2008. Warmth and competence as universal dimensions of social perception: The stereotype content model and the BIAS map. Advances in Experimental Social Psychology, 40: 61-149.

Cuddy, A. J. C., Fiske, S. T., Kwan, V. S. Y., Glick, P., Demoulin, S., Leyens, J.-P., Bond, M. H., Croizet, J.-C., Ellemers, N., Sleebos, E., Htun, T. T., Kim, H.-J., Maio, G., Perry, J., Petkova, K., Todorov, V., Rodríguez-Bailón, R., Morales, E., Moya, M., Palacios, M., Smith, V., Perez, R., Vala, J. , \& Ziegler, R. 2009. Stereotype content model across cultures: Towards universal similarities and some differences. British Journal of Social Psychology, 48(1): 1-33. 
Diamantopoulos, A., Smith, G., \& Grime, I. 2005. The impact of brand extensions on brand personality: Experimental evidence. European Journal of Marketing, 39(1/2): 129-149.

Dimofte, C. V. 2010. Implicit measures of consumer cognition: A review. Psychology and Marketing, 27(10): 921-937.

Dodds, W. B., Monroe, K. B., \& Grewal, D. 1991. Effects of price, brand, and store information on buyers' product evaluations. Journal of Marketing Research, 28(3): 307-319.

Fazio, R. H., \& Olson, M. A. 2003. Implicit measures in social cognition research: Their meaning and use. Annual Review of Psychology, 54(1): 297-327.

Fiske, S. T., Cuddy, A. J., \& Glick, P. 2007. Universal dimensions of social cognition: Warmth and competence. Trends in Cognitive Sciences, 11(2): 77-83.

Fiske, S. T., Cuddy, A. J. C., Glick, P., \& Xu, J. 2002. A model of (often mixed) stereotype content: Competence and warmth respectively follow from perceived status and competition. Journal of Personality and Social Psychology, 82(6): 878-902.

Florack, A., Scarabis, M., \& Bless, H. 2001. When do associations matter? The use of automatic associations toward ethnic groups in person judgments. Journal of Experimental Social Psychology, 37(6): 518-524.

Friese, M., Hofmann, W., \& Wänke, M. 2008. When impulses take over: Moderated predictive validity of explicit and implicit attitude measures in predicting food choice and consumption behaviour. British Journal of Social Psychology, 47(3): 397-419.

Gawronski, B. 2009. Ten frequently asked questions about implicit measures and their frequently supposed, but not entirely correct answers. Canadian Psychology, 50(3): 141-150.

Gawronski, B., \& Bodenhausen, G. V. 2006. Associative and propositional processes in evaluation: An integrative review of implicit and explicit attitude change. Psychological Bulletin, 132(5): 692-731.

Glick, P., Fiske, S. T., Abrams, D., Dardenne, B., Ferreira, M. C., Gonzalez, R., Hachfeld, C., Huang, L.-l., Hutchison, P., Kim, H.-J., Manganelli, A. M., Masser, B., Mucchi-Faina, A., Okiebisu, S., Rouhana, N., Saiz, J. L., Sakalli-Ugurlu, N., Volpato, C., Yamamoto, M., \& Yzerbyt, V. 2006. 
Anti-American sentiment and America's perceived intent to dominate: An 11-nation study. Basic and Applied Social Psychology, 28(4): 363-373.

Greenwald, A. G., \& Banaji, M. R. 1995. Implicit social cognition: Attitudes, self-esteem, and stereotypes. Psychological Review, 102(1): 4-27.

Greenwald, A. G., McGhee, D. E., \& Schwartz, J. L. K. 1998. Measuring individual differences in implicit cognition: The implicit association test. Journal of Personality and Social Psychology, 74(6): 1464-1480.

Greenwald, A. G., Nosek, B. A., \& Banaji, M. R. 2003. Understanding and using the implicit association test: I. An improved scoring algorithm. Journal of Personality and Social Psychology, 85(2): 197-216.

Greenwald, A. G., Poehlman, T. A., Uhlmann, E. L., \& Banaji, M. R. 2009. Understanding and using the Implicit Association Test: III. Meta-analysis of predictive validity. Journal of Personality and Social Psychology, 97(1): 17-41.

Hayes, A. F. 2013. Introduction to mediation, moderation, and conditional process analysis: A regression-based approach. New York, NY: Guilford Press.

Halkias, G., Davvetas, V., \& Diamantopoulos, A. 2016. The interplay between country stereotypes and perceived brand globalness/localness as drivers of brand preference. Journal of Business Research 69(9): 3621-3628.

Herz, M. F., \& Diamantopoulos, A. 2013a. Country-specific associations made by consumers: A dualcoding theory perspective. Journal of International Marketing, 21(3): 95-121.

Herz, M. F., \& Diamantopoulos, A. 2013b. Activation of country stereotypes: Automaticity, consonance, and impact. Journal of the Academy of Marketing Science, 41(4): 400-417.

Jaffe, E. D., \& Nebenzahl, I. D. 2006. National image and competitive advantage: The theory and practice of place branding, (2nd ed.). Copenhagen: Copenhagen Business School Press.

Josiassen, A., Lukas, B. A., Whitwell, G. J., \& Assaf, A. G. 2013. The halo model of origin images: Conceptualisation and initial empirical test. Journal of Consumer Behaviour, 12(4): 253-266. 
Judd, C. M., James-Hawkins, L., Yzerbyt, V., \& Kashima, Y. 2005. Fundamental dimensions of social judgment: Understanding the relations between judgments of competence and warmth. Journal of Personality and Social Psychology, 89(6): 899.

Karpinski, A., \& Steinman, R. B. 2006. The single category implicit association test as a measure of implicit social cognition. Journal of Personality and Social Psychology, 91(1): 16-32.

Kervyn, N., Yzerbyt, V. Y., Demoulin, S., \& Judd, C. M. 2008. Competence and warmth in context: The compensatory nature of stereotypic views of national groups. European Journal of Social Psychology, 38(7): 1175-1183.

Levy, S. R., Stroessner, S. J., \& Dweck, C. S. 1998. Stereotype formation and endorsement: The role of implicit theories. Journal of Personality and Social Psychology, 74(6): 1421-1436.

Liu, S. S., \& Johnson, K. F. 2005. The automatic country-of-origin effects on brand evaluations. Journal of Advertising, 34(1): 87-97.

Magnusson, P., \& Westjohn, S. A. 2011. Is there a country-of-origin theory? In S. C. Jain \& D. A. Griffith (Eds), Handbook of research in international marketing: 292-316. Northampton, MA: Edward Elgar Publishing, Inc.

Maher, A. A., \& Carter, L. L. 2011. The affective and cognitive components of country image: Perceptions of American products in Kuwait. International Marketing Review, 28(6): 559-580.

Maheswaran, D. 1994. Country of origin as a stereotype: Effects of consumer expertise and attribute strength on product evaluations. Journal of Consumer Research, 21(2): 354-365.

Maheswaran, D., \& Chen, C. Y. 2009. Nation equity: Country-of-origin effects and globalization. In M. Kotabe \& K. Kelsen (Eds), Handbook of international marketing: 91-113. Thousand Oaks, CA: Sage.

Martin, B. A. S., Lee, M. S. W., \& Lacey, C. 2011. Countering negative country of origin effects using imagery processing. Journal of Consumer Behaviour, 10(2): 80-92.

Oberecker, E. M., Riefler, P., \& Diamantopoulos, A. 2008. The consumer affinity construct: Conceptualization, qualitative investigation, and research agenda. Journal of International Marketing, 16(3): 23-56. 
Parker, A. M., Bruine de Bruin, W., \& Fischhoff, B. 2007. Maximizers versus satisficers: Decisionmaking styles, competence, and outcomes. Judgment and Decision Making, 2(6): 342-350.

Podsakoff, P. M., MacKenzie, S. B., \& Podsakoff, N. P. 2012. Sources of method bias in social science research and recommendations on how to control it. Annual Review of Psychology, 63: 539-569.

Reisen, N., Hoffrage, U., \& Mast, F. W. 2008. Identifying decision strategies in a consumer choice situation. Judgment and Decision Making, 3(8): 641-658.

Roth, K. P., \& Diamantopoulos, A. 2009. Advancing the country image construct. Journal of Business Research, 62(7): 726-740.

Samiee, S. 2010. Advancing the country image construct - A commentary essay. Journal of Business Research, 63(4): 442-445.

Samiee, S. 2011. Resolving the impasse regarding research on the origins of products and brands. International Marketing Review, 28(5): 473-485.

Samiee, S., \& Leonidou, L. C. 2011. Relevance and rigor in international marketing research: Developments in product and brand origin line of inquiry. In S. C. Jain \& D. A. Griffith (Eds), Handbook of research in international marketing: 68-87. Northampton, MA: Edward Elgar Publishing, Inc.

Scarabis, M., Florack, A., \& Gosejohann, S. 2006. When consumers follow their feelings: The impact of affective or cognitive focus on the basis of consumers’ choice. Psychology \& Marketing, 23(12): 1015-1034.

Strack, F., \& Deutsch, R. 2004. Reflective and impulsive determinants of social behavior. Personality and Social Psychology Review, 8(3): 220-247.

Usunier, J.-C. 2006. Relevance in business research: The case of country-of-origin research in marketing, European Management Review, 3(1): 60-73.

Ybarra, O., Chan, E., \& Park, D. 2001. Young and old adults' concerns about morality and competence. Motivation and Emotion, 25(2): 85-100.

Zeugner-Roth, K. P., Žabkar, V., \& Diamantopoulos, A. 2015. Consumer ethnocentrism, national identity, and consumer cosmopolitanism as drivers of consumer behavior: A social identity theory perspective. Journal of International Marketing, 23(2): 25-54. 
Figure 1 Research model in Study 1.

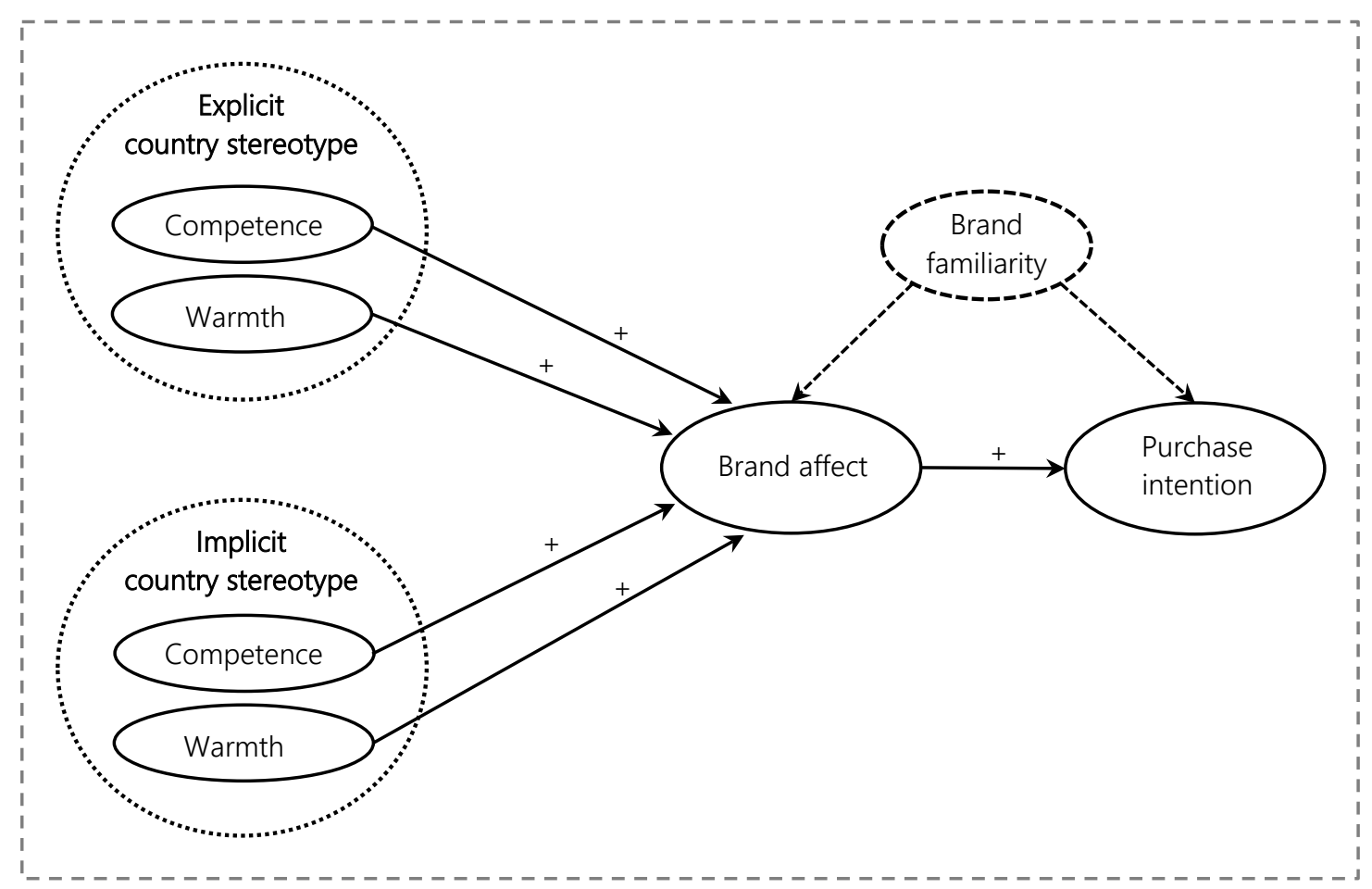

Note. Brand familiarity is used as a covariate. 
Figure 2 Explicit and implicit country stereotypes in Study 1 (based on z-scores).

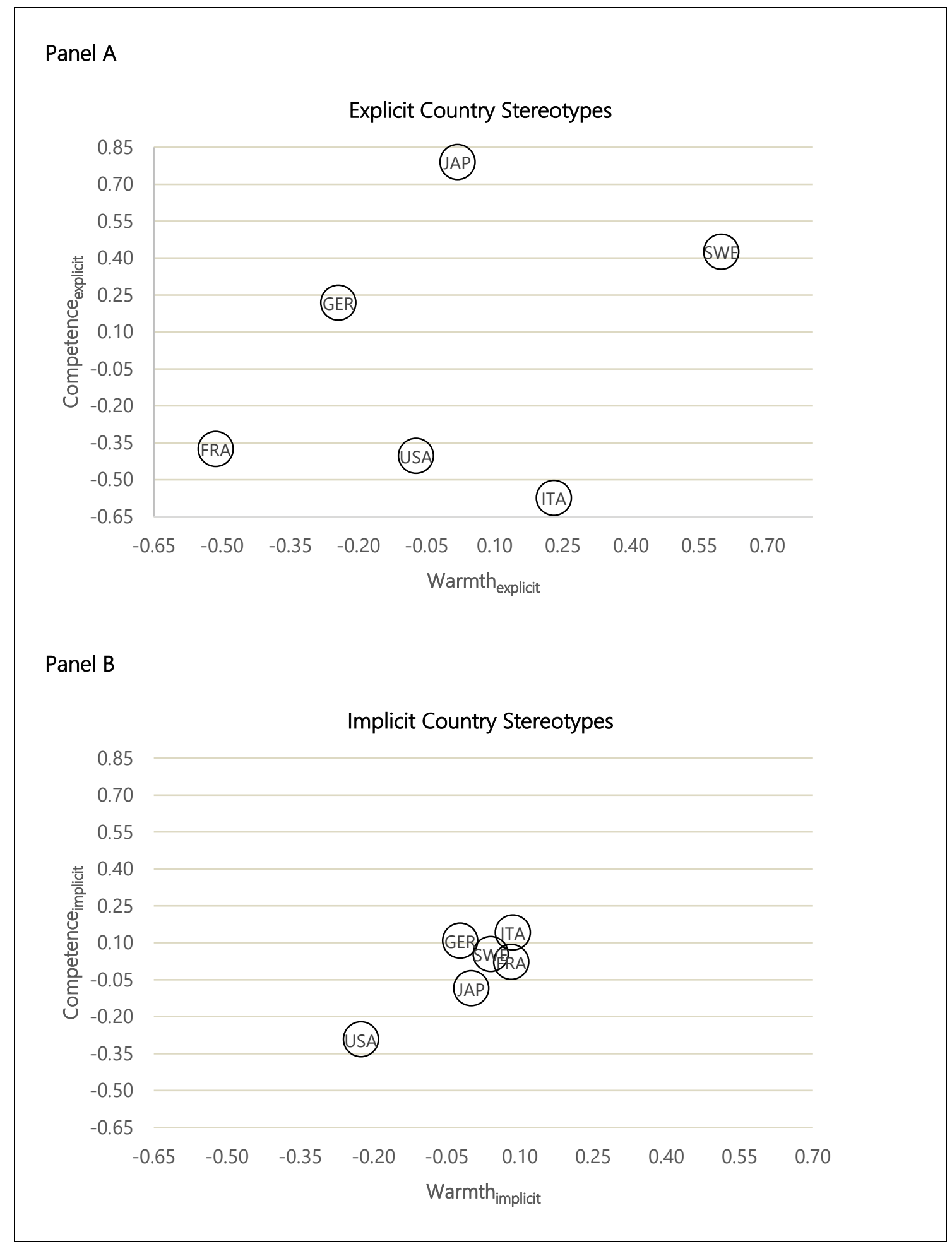


Table 1 Measurement properties of the model variables.

Country stereotype: Warmth

$\alpha=.898, \mathrm{CR}=.92, \mathrm{AVE}=.75$

Adapted from Fiske et al. (2002)

The attribute friendly describes [target country] .947*

The attribute good-natured describes [target country] .840*

The attribute kind describes [target country] $.814^{*}$

The attribute warm describes [target country] .864*

\section{Country stereotype: Competence $\mathrm{a}^{\mathrm{a}}$}

$\alpha=.894, \mathrm{CR}=.92, \mathrm{AVE}=.74$

Adapted from Fiske et al. (2002)

The attribute capable describes [target country] $\quad .916^{*}$

The attribute competent describes [target country] .818*

The attribute efficient describes [target country] .899*

The attribute intelligent describes [target country] .810*

\section{Brand affect ${ }^{\mathrm{a}}$}

Adapted from Chaudhuri \& Holbrook (2001)

$\alpha=.912, \mathrm{CR}=.93, \mathrm{AVE}=.81$

This brand makes me feel good.

.886*

This brand makes me happy.

$.870 *$

This brand gives me pleasure.

$.947 *$

Purchase intention $^{\mathrm{a}}$

$\alpha=.973, \mathrm{CR}=.98, \mathrm{AVE}=.95$

Adapted from Dodds, Monroe, \& Grewal (1991)

I will likely buy this brand. $\quad .982 *$

The probability that I would consider buying this brand is high. .985*

I am willing to buy this brand. 959*

Brand familiarity

$\alpha=.950, \mathrm{CR}=.96, \mathrm{AVE}=.90$

Adapted from Diamantopoulos, Smith, \& Grime (2005)

I am not at all/very familiar with this brand. $\quad .958^{*}$

I believe I am not at all/very informed about this brand. $.977^{*}$

I consider myself to be inexperienced/experienced with regard to this brand. .903*

$* p<.001$

a Scale item anchors were totally disagree/totally agree.

Note. Only explicitly measured country stereotypes are reported. The $d$-scores for the warmth and competence dimensions based on the SC-IAT were specified as single-item constructs. Country stereotype items were measured on five-point scales and all other items on seven-point scales. Column entries are standardized factor loadings. $\alpha=$ Cronbach's alpha; CR = construct reliability; AVE = average variance extracted. 
Table 2 Discriminant validity assessment.

\begin{tabular}{llllllll}
\hline Construct & Mean & SD & $\mathbf{1}$ & $\mathbf{2}$ & $\mathbf{3}$ & $\mathbf{4}$ & $\mathbf{5}$ \\
$\mathbf{1}$ Warmth $_{\text {explicit }}$ & 3.23 & 0.82 & $\mathbf{. 7 5}$ & & & & \\
${\text { 2 } \text { Competence }_{\text {explicit }}}$ Brand affect & 3.50 & 0.77 & .25 &. $\mathbf{7 4}$ & & & \\
$\mathbf{4}$ Purchase intention & 3.81 & 1.54 & .03 & .08 & $\mathbf{. 8 1}$ & & \\
$\mathbf{5}$ Brand familiarity & 3.88 & 1.84 & .03 & .06 & .46 & $\mathbf{. 9 5}$ & \\
\hline
\end{tabular}

Note. Bold numbers on the diagonal show the AVE. Numbers on the off-diagonal represent the squared correlation between the constructs. Only explicitly-measured country stereotypes are reported. The $d$-scores for the warmth and competence dimensions based on the SC-IAT were specified as single-item constructs. 
Table 3 Indirect effects of country stereotypes on purchase intention through brand affect.

\begin{tabular}{|c|c|}
\hline Path & Effect estimate \\
\hline \multicolumn{2}{|l|}{ Indirect effects: } \\
\hline Warmth $_{\text {explicit }} \rightarrow$ brand affect $\rightarrow$ purchase intention & -.001 \\
\hline Competence $_{\text {explicit }} \rightarrow$ brand affect $\rightarrow$ purchase intention & $.082 * *$ \\
\hline Warmth $_{\text {implicit }} \rightarrow$ brand affect $\rightarrow$ purchase intention & .032 \\
\hline Competence $_{\text {implicit }} \rightarrow$ brand affect $\rightarrow$ purchase intention & $.043^{*}$ \\
\hline \multicolumn{2}{|l|}{ Control: } \\
\hline Brand familiarity $\rightarrow$ brand affect & $.431 * * *$ \\
\hline Brand familiarity $\rightarrow$ purchase intention & $.472 * * *$ \\
\hline
\end{tabular}

$* p<.05,{ }^{* *} p<.01, * * * p<.001$

Note. Values represent standardized coefficients. Indirect effects are based on normal theory testing (Sobel tests) as estimated by the structural model. 
Table 4 Explicit and implicit country stereotypes as predictors of product choice likelihood in deliberate (H4) and spontaneous (H5) choice conditions.

\begin{tabular}{lccc}
\hline Predictor & $\boldsymbol{\beta}$ (standardized) & $\boldsymbol{t}$-value & $\boldsymbol{p}$ \\
\hline Deliberate $(n=132)$ & & & \\
Warmth $_{\text {implicit }}$ & .001 & 0.013 & .990 \\
Competence $_{\text {implicit }}$ & .125 & 1.368 & .174 \\
Warmth $_{\text {explicit }}$ & .063 & 0.714 & .476 \\
Competence $_{\text {explicit }}$ & .236 & 2.724 & .007 \\
Spontanous $(n=150)$ & & & \\
Warmth & & & \\
$_{\text {implicit }}$ & .246 & 2.873 & .005 \\
Warmptence $_{\text {implicit }}$ & -.119 & -1.397 & .165 \\
Complicit & -.145 & -1.704 & .091 \\
& -.014 & -0.163 & .870 \\
\hline
\end{tabular}

